\title{
Determinants influencing customers' decision to use mobile payment services: The case of Vietnam
}

\author{
Huu Nghi Phana, Manh Dung Tran ${ }^{a}$, Van Hoa Hoanga and Thanh Dung Dang ${ }^{\mathrm{b}}$
}

\author{
${ }^{a}$ National Economics University, Vietnam

\begin{tabular}{l} 
Article history: \\
Received: February 16, 2020 \\
Received in revised format: \\
March 222020 \\
Accepted: March 22, 2020 \\
Available online: \\
March 25, 2020 \\
\hline Keywords: \\
Mobile payments \\
Customer's decision \\
Vietnam
\end{tabular}

\section{Article history:} \\ Received: February 16, 202 \\ Received in revised format: \\ Accepted: March 22, 2020 \\ Available online: \\ Keywords: \\ Customer's decision \\ Vietnam
}

${ }^{b}$ Vietnam Maritime Commercial Joint Stock Bank, Vietnam

\section{A B S T R A C T}

This study is conducted to investigate the impact levels of determinants on customers' decision to use payment services via mobile devices in Hanoi, Vietnam. Data were collected from a survey of people living in Hanoi city of Vietnam who may or not use mobile payment services. Based on the theory of technology acceptance and use (UTAUT) developed, we design a research model with six determinants including expected efficiency, effort expectations, social impact, safety and security, perceived costs and supplier reputation. The results show that determinants of expected efficiency, expected effort, social impact, safety and security and supplier reputation (except perceived costs) had positive impacts on the decision of customer. However, the degree and order of impact varies between two groups of unused and already used customers. In particular, the determinants of effort of expectation, safety and security, reputation of suppliers had the strongest impacts on the decisions of customers in both groups in using payment services through mobile device. Based on the findings, we give suggestions for managers and service providers in developing this kind of service in Hanoi, Vietnam as a case study for emerging countries.

\section{Introduction}

Currently, the Industrial Revolution 4.0 is taking place strongly, completely changing all aspects of economies, the invention of technologies has helped change the way people communicate and interact, leading to changes in distribution channels, sales networks and product and service design, including payment via mobile devices. This is a newly developed electronic payment method in Vietnam, contributing to the promotion of cashless payment in Vietnam. With this service, users minimize the operations when making transactions, limit errors and risks during the payment of goods and service purchases, and bring a completely different experience from the traditional payment methods. Mobile payment solutions in Vietnam are increasingly diverse such as mPos, QR Pay, mobile banking services, e-wallets, touchless payment applications. Although the Vietnamese market has great potential, there is currently no solution for payment via mobile devices that is considered prominent and creating a trend. The providers of this service also face some limitations. The units with the technological potential to provide mobile payment services are telecommunications firms. However, they do not have the function of providing payment services. Fintech firms have technology background, some have been licensed by the State Bank of Vietnam to join the payment field but the legal regulations are not complete and the customer base is limited. Besides, people's cash habit is also common as well as the lack of knowledge about this new field of complex technology application, leading to concerns about possible risks. The majority of Vietnam's population is in rural areas, the number of people without bank accounts is still very large and has not had much access to payment technologies. Accelerating the change of payment habit requires the strategy and coordination of many parties such as state agencies, banks, Fintech firms with a focus on customers. Based on the above facts, 
understanding and identifying the interests of customers when using mobile payment services and the determinants influencing customer decisions in using payment services via mobile devices is essential for banking activities in general and payment in particular. Determinants influencing the use of payment services via mobile devices have attracted special attention of many researchers. They have applied the fundamental theories such as TPB, TAM, TRA, IDT, UTAUT. The results of studies have also pointed out many determinants influencing the use of payment services via mobile devices of customers such as safety, security, usefulness, ease of use. Now, some scientists have investigated this issue in the context of Vietnam and chose to apply fundamental theories such as TPB, TAM such as studies of Nguyen et al. (2015), Nguyen et al. (2016), Pham \& Liu (2016). In order to facilitate the promotion of payment on mobile devices in Vietnam, the identification and appreciation of the degree of influence of each determinant on the use of this service are very important to the parties involved. On the other hand, the current and potential customers are mainly concentrated in big cities like Hanoi and Ho Chi Minh of Vietnam as an emerging country, while in smaller provinces and cities, rural areas. In remote areas, access to traditional banking services is still small and limited, so payment via mobile devices is almost new. In particular, Hanoi is one of the most developed cities in the country, bringing together most industries, services as well as great payment needs of the people. Therefore, in the scope of this research, we apply the theoretical model of acceptance and use of UTAUT technology of Venkatesh et al. (2003) with adjustments and supplements to suit the environment of Vietnam to explore determinants influencing customers' decision to use mobile payment services.

\section{Literature review}

\subsection{General theory of mobile payments}

In this group, the studies focus on developing a theoretical framework to be applied in practice, from which to draw empirical conclusions or propose expected research models for mobile payments. Some scientists such as Dahlberg et al. (2008), Ghezzi et al. (2010) synthesized the theory of mobile payment, analyzed the various determinants influencing the mobile payment market and propose future research directions for this new field. Some organizations such as OECD (2012), EPC (2017) offer a theoretical framework for mobile payment including concepts, participants, benefits, and difficulties, risks, new technologies, etc. All these studies show that the different perspectives when gathered will be able to provide useful multidimensional insights to analyze and better understand mobile payments. Each research generally contributes the clarification of mobile payment. However, science and technology are increasingly developing, leading to its related services (including payment via mobile devices), constantly upgrading and innovating.

\subsection{Determinants influencing the acceptance of using payment services via mobile devices}

Studies in this direction have been based on Reasonable Action Theory (TRA), The Proposed Behavioral Theory (TRA), The Innovation Model Theory (IDT), The Combined Theory of Acceptance and Use Technology (UTAUT) and Technology Acceptance Model (TAM) to explain the acceptance of the use of mobile payment services. The author synthesizes a number of influencing determinants that have been used in these studies (appendix), thereby drawing out some of the following remarks:

First, there are many determinants influencing customers' decision to use mobile payment services such as customer-related determinants (such as gender, income, age, knowledge, and beliefs, information, attitudes), service-related determinants (such as ease of use, usefulness, compatibility, mobility, cost), security-related determinants (such as security and risk). Each study has a difference in the selection of influencing determinants, this is due to differences in background theory, study context, sample size, people surveyed, study duration. Therefore, leading to different research results, even contradictions. However, the diversity of studies has facilitated a better understanding and a more comprehensive view of mobile payments and the usage culture of each country. Second, a number of determinants influencing many studies that prove to influence customers' intention and decision to use such as expected efficiency (usefulness), expected effort (ease of use), attitudes, beliefs, social influence, risks. These are all key determinants in the underlying theories presented above. Despite the different names, some of the similarities in nature, such as effective expectations (UTAUT), are similar to perceived usefulness (TAM) and relative advantage (IDT). Therefore, although the researches apply different background theory, there are overlapping determinants. This research is mainly focused on finding determinants that influence the decision of potential consumers to use mobile payment services without research or incomplete research on personal determinants. Determinants influencing the acceptance of current consumer use.

\subsection{Basic theories}

There are many theoretical models of technology adoption and use (TRA; TPB; TAM; UTAUT), these are classical theoretical models to measure behavioral intent and actual use of technology of consumers. Although there are advantages and limitations in explaining behavior using new technology, the following theories often overcome the previous limitations or extensions of the theory. This leads to similarities and differences between these theories. Specifically, TRA, TPB, TAM follow the direction of explaining the relationship of attitude - intention - behavior of accepting technology but each theory chooses different influencing determinants to study. TAM, IDT, UTAUT also have similarities with the perceived usefulness factor of TAM similar to the relative advantage of IDT and the expected efficiency of UTAUT. These determinants all influence the intention to use and use behavior, in addition to more or less related to TRA in explaining consumer behavior, which is derived from the effectiveness of that behavior. Besides, ATM's perceived ease of use factor is similar to IDT's complexity factor as well as UTAUT's expected effort factor, all influencing the intention and behavior. Within the scope of the study, the author 
chooses the UTAUT theory as a research platform to explain the customer's decision to use payment services via mobile devices. The reason is that (i) UTAUT was introduced after theories such as TPB, TAM, IDT and built on these theories themselves, so there was a limitation or expansion of the previous theories. There is still a similar conceptual concept, the scale of the previously tested variables; (ii) according to the research results of Venkatesh et al. (2003), UTAUT explained the most effective technology adoption intent and behavior, accounting for $70 \%$ of the differences in this interpretation; (iii) in Vietnam, mobile payment services are one of the services with the application of new technologies, while the habit of using cash is still popular by people consumption is easily affected by the surroundings, afraid of complex difficulties, these in UTAUT theory are expressed through determinants such as expected efficiency, expected effort, social influence, good condition.

\section{Unified theory of acceptance and use of technology (UTAUT)}

Venkatesh et al. (2003) based on theories such as TRA; TPB; TAM; integration of TPB and TAM, the theory of innovation dissemination (IDT), motivational model (MM), computer use model (MPCU), and social awareness theory (SCT) propose a The new theory is called the unified theory of acceptance and use of technology (UTAUT) for the purpose of explaining technology intentions and behaviors. UTAUT is most influenced by TRA, TPB and TAM theories. Venkatesh et al. (2003) proposed that individual reactions in the use of technology directly impact an individual's intention to use, followed by an impact on actual use. Thereby, Venkatesh et al. (2003) demonstrate that this model is optimal in explaining technology intentions. The main determinants are expected effectiveness, expected effort, social influence and favorable conditions. Expected effectiveness is that individuals believe that using technology will help them to achieve higher work efficiency. The expected effort describes how easy it is to participate in and use the system. Social influence is an important issue that affects the individual's perception that they will use the new system. Favorable conditions are understood as the support from organizations and facilities that will enable individuals to easily use the technology.

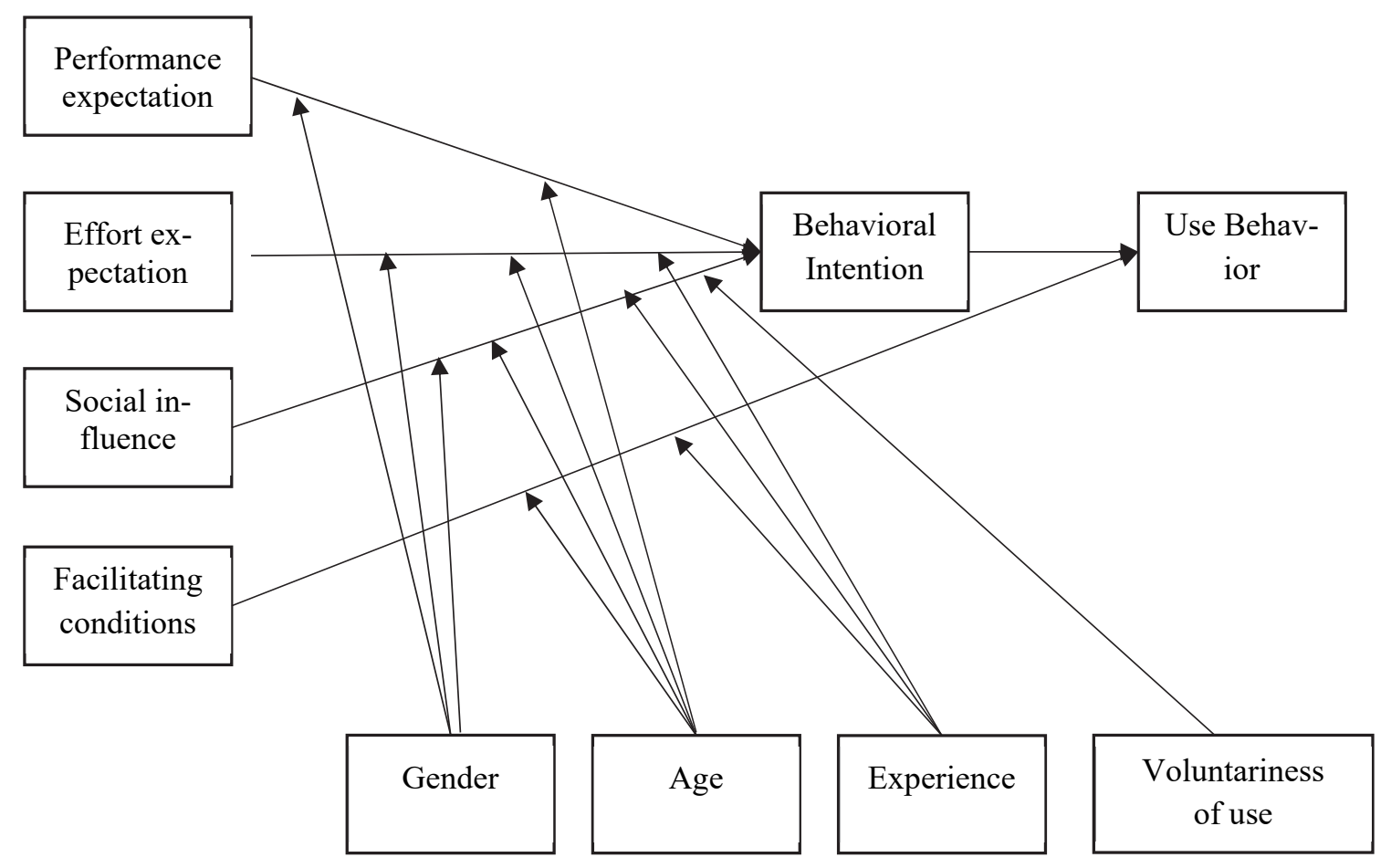

Fig. 1. Theoretical model of technology adoption and use (Venkatesh et al., 2003)

There are also a number of additional determinants given in the model to further consider the impact on intent and behavior used, such as gender, age, experience, and volunteer use. UTAUT continues to expand into UTAUT2 by adding motivational determinants, value, price, and habits Venkatesh et al. (2012). Due to the fact that there may be other determinants that influence an individual's intention to use technology. Research on consumer acceptance of payment services via mobile devices has been conducted by several studies using UTAUT theory such as Slade et al. (2015a, 2015b), Baptista (2016), Abrahão \& et al (2016), Tossy (2014); Yeh and Tseng (2017). The research results have proved the author's proposals and showed the flexible expansion of UTAUT in each specific case study.

In fact, in addition to the determinants in the above models, there are other determinants that influence customers' decision to use payment via mobile devices. Therefore, many studies have expanded the combination and development of the above models by adding new determinants. 


\section{Model and research methodology}

\subsection{Model and hypotheses}

Based on the theory of technology acceptance and use by Venkatesh et al. (2003), we focus on additional research to expand and deepen UTAUT by introducing new determinants, explanations and determinations redefine existing determinants in the model and find out the importance of each factor.

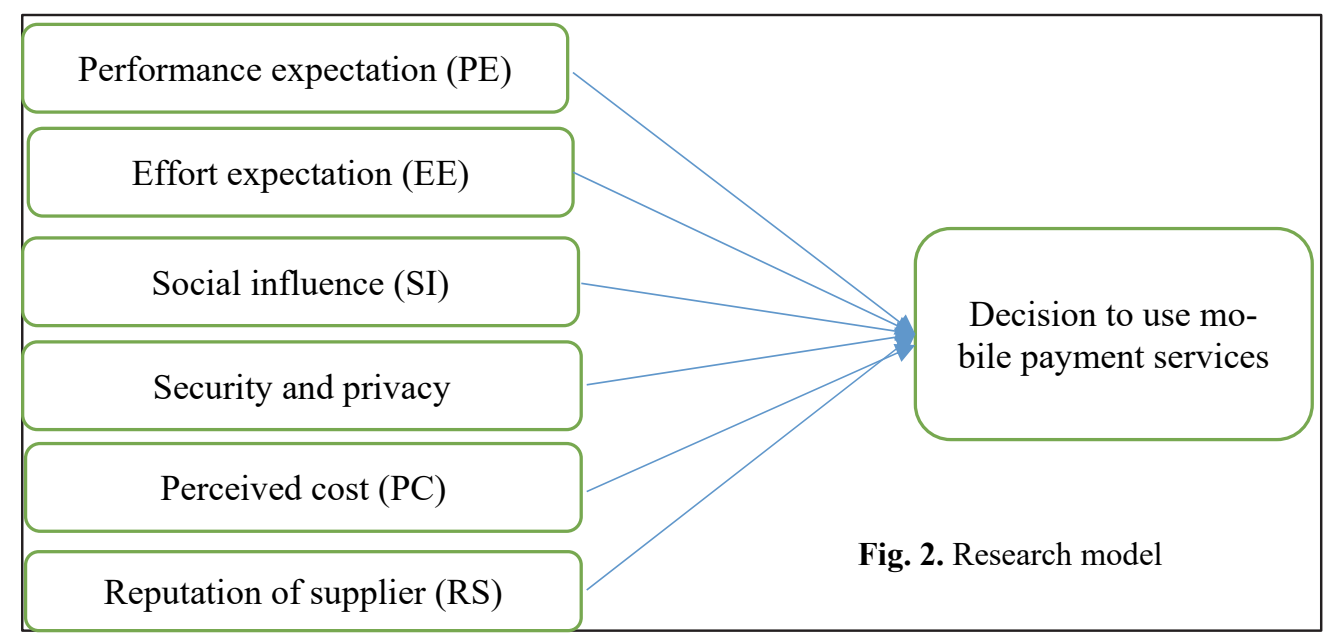

In this study, the three root elements of the UTAUT model include expectation effort, expected efficiency and social influence. Looking at the observed variables proposed by Venkatesh et al. (2003), the author observed the interaction of the expected effort factor and the compatibility of the facilitation determinant; learning to use the easy system of the expectation effort factor and the necessary knowledge of the facilitation factor have similarities. In addition, from the review of the influencing determinants above, it can be seen that the expected effort factor and favorable conditions simultaneously manifested both influence and influence in previous studies. Therefore, we did not use the favorable condition of the original model but the observed variables of the effort factor expected an appropriate adjustment for this study. The three newly added determinants are safety and security, perceived cost and supplier reputation. These are determinants proposed by experts and customers in addition to the determinants of the above model UTAUT when deeply interviewed about payment services via mobile devices. In addition, these determinants have been included in the research and verified in specific situations.

\section{Decision to use services}

Most of the current studies on the acceptance of mobile service use the determinants that directly influence the intention / intention to use according to the aforementioned theories. Davis et al. (1989) suggested that intention to use is the readiness of a person to adopt technology. In UTAUT theory, Venkatesh et al. (2003) studied the intent of customer behavior, that is, referring to the intention of effective use of consumers with a product or service in the future. The number of studies can be mentioned as: Hahn \& Kodó (2017), Abrahão et al (2016), Baptista (2016), Pham \& Liu (2016), Slade et al .(2015a, b), Koenig-Lewis et al. (2015). In addition, there are a few studies on determinants that influence usage. Usage level is understood as the frequency of regular use by customers about a service. Zhang et al. (2018) studied the frequency of use, the extent of use, and the value used for actual use. Do (2016) studies both the intention to use and the extent to which customers use Internet Banking in Vietnam. In addition, there is also Al-Qeisi (2009); Al-Qeisi \& Al-Abdallah (2013) also studied the extent of Internet banking usage. With the aim of the paper, to consider the determinants influencing customers, have been using mobile payment services, the author expanded the intention of using the UTAUT theory to determine Usage plan includes both intention to use and level of service use.

\subsubsection{Performance expectation}

The performance expectation in UTAUT2 is defined as the extent to which the use of technology will benefit customers when performing certain activities (Venkatesh et al., 2012). The expected effect is the extent of the benefits gained from the use of technology in carrying out certain activities (Yeh \& Tseng, 2017). In addition to being easy to use, customers will be concerned about the benefits of new services compared to traditional services (Awamleh \& Fernandes, 2006), so expected effectiveness is considered one of the key Determinants determine the intention to use new services such as mobile payment services of customers. The results of Baptista (2016) show that the expected effect has a positive effect on the intention of behavior, expressed consistently with research such as Wang \& Yi (2012); Slade et al. (2015a,b); Abrahão et al. (2016); Tossy (2014); Yeh \& Tseng (2017). This implies that the degree of benefit that mobile payments bring in the performance of payment tasks has a major impact on accepting mobile payments. Consumers can use mobile payment services once they believe that using such a system can increase efficiency in the way they conduct various transactions. Within the scope of this article, the expected effect is that customers believe that the use of payment via mobile devices will increase their work efficiency. 
H1: Performance expectation has a positive impact on customer decisions in using mobile payment.

\subsubsection{Effort expectation}

Effort expectation is defined as the degree of ease with which a user's system is used (Venkatesh et al., 2012). Imran et al. (2019) believe that an easy and reliable payment system always encourages customers to buy online. For modern services such as mobile payment, one thing customers will surely ask is whether it is easy to use or not; this is an important factor influencing customers' intention to use mobile payment services (Moore \& Benbasat, 1991). When users feel that mobile payment is easy to use and does not require much effort, they have higher expectations to achieve the desired performance (Venkatesh et al., 2003). Moreover, this has a great impact in the early stages of service deployment and will gradually reduce the level of influence when going through the next stage by users who are already familiar with mobile payment services (Venkatesh et al. 2003). Expected effort is one of the most important predictors of the intention to use mobile payment in the research of Wang and Yi (2012), Oye et al. (2014), Abrahão et al. (2016). Whereas the results of Tossy (2014), Slade et al (2015a, b), Baptista (2016), Yeh and Tseng (2017) do not reflect get this relationship. Tossy (2014) explains the results of this study because respondents in Tanzania have used mobile payment systems to pay for other services such as electricity bills, TV channels and services. Similarly, it is not difficult to pay for the exam fee using this service. And Yeh \& Tseng (2017) stated that university students in Taiwan do not think that the use of easy mobile payment will affect the intention to use mobile payment services by college students. They have been accustomed to using smartphones for years, so they believe that there are no difficulties using the mobile payment system. However, the expected effort has a positive effect on the expected efficiency of mobile payments (Baptista, 2016). Within the scope of this article, the expected effort is understood as the degree to which customers easily log in and use the mobile payment service.

\section{H2: Effort expectation has a positive impact on customers' decisions to use mobile payment services.}

\subsubsection{Social influence}

Social influence occurs when consumer behavior is influenced by others (Mun et al., 2017). Social influence is defined as the degree of influence that other people's opinions may have on the application of a given system. Social influence refers to the extent to which consumers' decision to adopt and use a mobile payment system is influenced by other individuals in the family, community, workplace, etc. (Venkatesh et al., 2003). According to Dahlberg et al. (2008), in evaluating the acceptance of technological innovation, it is necessary to consider the social influence of decision makers. This is especially in the case of the early stages because users lack reliable information about innovation in detail. Moreover, users are more likely to recommend the service to others if they are satisfied with the previous service (Fan et al., 2005). Social influence can have a positive and direct impact on customers intending to accept mobile payment services in the studies of Abrahão et al (2016); Mun et al. (2017); Tossy (2014), Baptista (2016); Slade et al. (2015a, b); Koenig-Lewis et al (2015). Research result of Yeh \& Tseng (2017) showed no impact on the intention to use mobile payment services. The reason is that students in Taiwan consider mobile payments a way to make purchases, so there's no need to consider other people's opinions (Yeh \& Tseng, 2017). Within the scope of this study, social influence is the feeling that a customer will feel and will use the mobile payment service influenced by others around them.

\section{H3: Social impact has a positive impact on customers' decisions to use mobile payment services.}

\subsubsection{Security and privacy}

Perceived security is a level of confidence that an organization will handle all transactions safely and securely with personal information (Hosein, 2009). Perceptual security in e-commerce transactions is defined as subjective assumptions of consumers about whether their personal and financial information will not be tampered with by third parties (Chellappa \& Pavlou, 2002). Kim et al. (2008) also found that the higher perceived security in the context of e-commerce, the lower the perceived risk and vice versa. Security threats in the context of online banking mainly occur through the network with data transmission and transaction attacks, moreover, they can be caused by improper access due to Third-party differences (Yousafzai et al., 2003). Research results of Luna et al. (2017) show that perceived security has a positive impact on consumers' intention to accept mobile payments via NFC technology in Brazil. Moreover, the research results of Hahn \& Kodó (2017) show that perceived security positively influences the intention of people who have never used mobile payment in Germany and Hungary; positively influencing the intent of people who used mobile payments in Germany, Hungary, and Sweden. Within the scope of this article, safety and confidentiality is considered as the level that customers believe that the payment via mobile devices of personal information is confidential and financial.

H4: Security and privacy have positive impacts on customers' decision to use payment services via mobile devices.

\subsubsection{Perceived cost}

The perceived cost is understood as the degree to which consumers believe that the use of mobile payment has to be paid (Luarn and Lin, 2005). Perceived cost refers to the cost of signing up and dealing with a mobile payment service. It also includes the ability of consumers to purchase a mobile device compatible with mobile payment services (adapted from Shafinah et al., 2013). Abrahão et al. (2016) examine the costs associated with the time, effort required to collect, analyze options 
and make decisions, as well as the development of relationships with new suppliers or new service. Mallat (2007) states that the cost of a payment transaction has a direct effect on consumer acceptance if the customer is the bearer. It also depends on the income of consumers, the cost can greatly affect the use of services by the lower income. Lesa (2016) found that costs have a negative impact on mobile payments but has little impact on consumers' intention to use mobile payments in Zambia. Because subjective standards of consumers go beyond cost sensitivity, they are not price sensitive when using mobile payment services. Research results of Abrahão et al. (2016) found no statistical significance at 5\% for perceived cost coefficients in the context of the study, contradicting the findings of Chong (2013) and Oye et al. (2014), but consistent with the study of Yang et al. (2012). Within the scope of the article, perceived cost is the extent to which customers believe that they must pay to use mobile payment services.

\section{H5: Perceived costs have negative impacts on customers' decisions to use mobile payment services.}

\subsubsection{Reputation of suppliers}

The reputation of mobile payment service providers is defined as the degree to which consumers rely on ability, honesty and fairness (Doney \& Canon, 1997). Lau \& Lee (1999) defines reputation as a person's opinion of the quality or reliability of a product or service. At the same time, the author also pointed out that customer appreciation will be spread quickly, good word of mouth can enhance service provider's reputation, and similarly, good reputation can strengthen trust of customers to service providers. Researchers believe that "reputation" is difficult to build but easy to lose without careful protection (Kartalia, 2000). When consumers have no previous experience of using a company's service, they rely on the reputation of the company to gauge trust (McKnight et al., 1998). Research by Truong et al. (2020) has shown that customers choose a highly reputable card provider in the hope of being a safe place of money. Chandra et al. (2010) and Xin et al. (2015) also published the results of determining service provider reputation as an important confidence building factor in the context of mobile payment. In the article, the reputation of a provider is the creditworthiness of customers for mobile payment service providers.

H6: Reputation of suppliers has a positive impact on customers' decisions to use payment services via mobile devices.

\subsection{Research approach}

We conduct quantitative research through official evaluation of the measurement scale by discovery factor analysis method and reliability coefficient; assess the trend and impact level between the dependent and independent variables.

The questionnaire outside the introduction includes two parts with the following content: Part 1: Questions related to general information including personal information and information about experience using payment services via the device be mobile in practice; Part 2: Questions related to the determinants that influence customer decisions on mobile payments, are answered using a 5-level Likert scale.

Sample size: The size of the sample depends on the analytical method. Because the subject uses the EFA discovery factor analysis method, according to the research of Hair et al. (2009), the minimum sample size is 5 times the total number of observed variables. The sample size must satisfy the formula: $n>=5 \times m=5 \times 21=105$. Thus, this research needs a minimum of 105 survey samples. To improve the reliability and accuracy of the research model, the sample will be selected as $n=223$. Subjects selected to participate in the study are aged 18 years and over, have experience in using internet and mobile devices, able to generate income and bank accounts, have / are using use payment via mobile devices or not yet used but know about payment via mobile devices in Hanoi. This area is densely populated, with many strata of population, ages, and diverse incomes, being one of the largest payment localities in the country.

\section{Results and discussion}

\subsection{Descriptive statistics}

We determine the number and percentage of responses to the demographic characteristics of the survey subjects.

Table 2

Description of demographic characteristics

\begin{tabular}{|c|c|c|c|c|}
\hline \multirow{2}{*}{ Classification } & \multicolumn{2}{|c|}{ Not using services } & \multicolumn{2}{|c|}{ Used/ using services } \\
\hline & Quantity & Percentage $(\%)$ & Quantity & Percentage (\%) \\
\hline \multicolumn{5}{|c|}{ Gender } \\
\hline Male & 31 & $32.29 \%$ & 39 & $30.71 \%$ \\
\hline Female & 65 & $67.71 \%$ & 88 & $69.29 \%$ \\
\hline \multicolumn{5}{|c|}{ Age } \\
\hline Below 40 & 71 & $73.96 \%$ & 119 & $93.70 \%$ \\
\hline Above 40 & 25 & $26.04 \%$ & 8 & $6.30 \%$ \\
\hline \multicolumn{5}{|c|}{ Income } \\
\hline Below 5 mil Vietnam dong (VND) & 53 & $55.21 \%$ & 19 & $14.96 \%$ \\
\hline Above 5 mil VND & 43 & $44.79 \%$ & 108 & $85.04 \%$ \\
\hline
\end{tabular}


Table 2

Description of demographic characteristics (Continued)

\begin{tabular}{|c|c|c|c|c|}
\hline \multirow{2}{*}{ Classification } & \multicolumn{2}{|c|}{ Not using services } & \multicolumn{2}{|c|}{ Used/ using services } \\
\hline & Quantity & Percentage $(\%)$ & Quantity & Percentage (\%) \\
\hline \multicolumn{5}{|c|}{ Academic level } \\
\hline Below university & 26 & $27.08 \%$ & 31 & $24.41 \%$ \\
\hline Above university & 70 & $72.92 \%$ & 96 & $75.59 \%$ \\
\hline \multicolumn{5}{|c|}{ Internet understanding level } \\
\hline Below normal & 5 & $5.21 \%$ & 3 & $2.36 \%$ \\
\hline Above normal & 91 & $94.79 \%$ & 124 & $97.64 \%$ \\
\hline \multicolumn{5}{|c|}{ Amount of time spent on mobile phones } \\
\hline Below 3 years & 21 & $21.88 \%$ & 18 & $14.17 \%$ \\
\hline Above 3 years & 75 & $78.13 \%$ & 109 & $85.83 \%$ \\
\hline Total & 96 & $100.00 \%$ & 127 & $100.00 \%$ \\
\hline
\end{tabular}

From Table 2, we see that both groups of customers who have not used and / have been using the service have a higher number of women than men, mostly young people ( $\leq 40$ years old) with university or higher education, a normal level of internet knowledge, and have had three years of smartphone use or more. Regarding income, while the group that has not used the service has an income of VND 5 million or less, accounting for $55.21 \%$, the group that has been using the service mainly has an income of VND 5 million or more (accounting for 85.04\%).

\subsection{Reliability tests of scale}

We use SPSS 20 software to assess the reliability of each scale. This result is divided among two groups of customers who are not using the service and have / are using mobile payment services. Among the research determinants, there is a perceived cost factor that cannot be assessed as the reliability of the scale because this factor has two observed variables (Nguyen, 2013).

Table 3

Test results of scale

\begin{tabular}{cccc}
\hline Scale & & Cronbach's Alpha & \\
\cline { 1 - 1 } PE & & Customers not using services & Customers having used/using services \\
EE & 0.732 & 0.764 & 0.748 \\
SI & 0.637 & 0.765 \\
SP & 0.887 & 0.782 & 0.836 \\
RS & 0.926 & 0.832 \\
\hline
\end{tabular}

Cronbach's Alpha coefficients of the scales are valued at $\geq 0.6$, thus meeting the requirements of reliability. Thus, no observed variables were removed, the survey scales for the two customer groups were highly reliable, which is a necessary condition for conducting further analyzes.

\subsection{Exploratory factor analysis}

After conducting the reliability analysis of the scale, we conducted a factor analysis. This result was divided among two groups of customers who were unused services and /have been using payment services via mobile devices.

Table 4

Factor rotation matrix

\begin{tabular}{|c|c|c|c|c|c|c|}
\hline \multicolumn{7}{|c|}{ Customers not using services } \\
\hline & 1 & 2 & 3 & 4 & 5 & 6 \\
\hline RS1 & 0.911 & & & & & \\
\hline RS2 & 0.893 & & & & & \\
\hline RS3 & 0.872 & & & & & \\
\hline SP1 & & 0.858 & & & & \\
\hline SP3 & & 0.855 & & & & \\
\hline SP2 & & 0.848 & & & & \\
\hline EE2 & & & 0.865 & & & \\
\hline EE3 & & & 0.765 & & & \\
\hline EE1 & & & 0.655 & & & \\
\hline PE1 & & & & 0.863 & & \\
\hline PE2 & & & & 0.762 & & \\
\hline PE3 & & & & 0.757 & & \\
\hline SI3 & & & & & 0.787 & \\
\hline SI2 & & & & & 0.770 & \\
\hline SI1 & & & & & 0.689 & \\
\hline PC1 & & & & & & 0.855 \\
\hline $\mathrm{PC} 2$ & & & & & & 0.706 \\
\hline
\end{tabular}

\begin{tabular}{|c|c|c|c|c|c|c|}
\hline \multicolumn{7}{|c|}{ Customers having used/using services } \\
\hline & 1 & 2 & 3 & 4 & 5 & 6 \\
\hline SP3 & 0.850 & & & & & \\
\hline SP2 & 0.803 & & & & & \\
\hline SP1 & 0.785 & & & & & \\
\hline RS1 & & 0.839 & & & & \\
\hline RS2 & & 0.773 & & & & \\
\hline RS3 & & 0.764 & & & & \\
\hline SI2 & & & 0.832 & & & \\
\hline SI1 & & & 0.816 & & & \\
\hline $\mathrm{SI} 3$ & & & 0.779 & & & \\
\hline EE2 & & & & 0.836 & & \\
\hline EE3 & & & & 0.795 & & \\
\hline EE1 & & & & 0.740 & & \\
\hline PE2 & & & & & 0.840 & \\
\hline PE1 & & & & & 0.822 & \\
\hline PE3 & & & & & 0.741 & \\
\hline PC1 & & & & & & 0.834 \\
\hline $\mathrm{PC} 2$ & & & & & & 0.758 \\
\hline
\end{tabular}


The results of the rotation matrix show that, 17 observed variables are grouped into 6 determinants, all observed variables have a factor load factor of Factor Loading $>0.5$, so factor analysis is appropriate and accepted with research data sets.

\subsection{Pearson correlation analysis}

Below is the analysis of Pearson correlation based on the sample size, which is presented in Table 5.

Table 5

Results of Pearson correlation analysis

\begin{tabular}{|c|c|c|c|c|c|c|c|c|}
\hline & Customers not using services (IU) & IU & $\mathrm{PE}$ & $\mathrm{EE}$ & SI & SP & $\mathrm{PC}$ & $\mathrm{RS}$ \\
\hline \multirow{2}{*}{ IU } & Pearson Correlation & 1 & $.344^{* *}$ & $.581^{* *}$ & $.261^{*}$ & $.587^{* *}$ & 0.048 & $.605^{* *}$ \\
\hline & Sig. (2-tailed) & & 0.001 & 0.000 & 0.010 & 0.000 & 0.643 & 0.000 \\
\hline \multicolumn{2}{|r|}{ Customers having used/ using services (RU) } & RU & $\mathrm{PE}$ & $\mathrm{EE}$ & SI & SP & $\mathrm{PC}$ & $\mathrm{RS}$ \\
\hline \multirow{2}{*}{ RU } & Pearson Correlation & 1 & $.331^{* *}$ & $.553^{* *}$ & $.423^{* *}$ & $.592^{* *}$ & -0.095 & $.605^{* *}$ \\
\hline & Sig. (2-tailed) & & 0.000 & 0.000 & 0.000 & 0.000 & 0.289 & 0.000 \\
\hline
\end{tabular}

**. Correlation is significant at the 0.01 level (2-tailed).

Sig. coefficient Pearson correlating the independent variables PE, EE, SI, SP, RS with the dependent variables IU and RU is respectively less than 0.05 . Thus, there is a linear relationship between these independent variables and the variable IU and RU.

Sig. coefficient the correlating between PC and IU, PC and RU is greater than 0.05 , so there is no linear correlation between $\mathrm{PC}$ and IU and RU. The PC variable will be removed when performing multiple linear regression analysis.

\subsection{Linear regression analysis}

For customers who have not used the service:

(i) Adjusted R2 value of 0.618 shows that the independent variable put in the regression process affects $61.8 \%$ of the change of the dependent variable, the rest is due to non-model variables and random errors.

(ii) Durbin-Watson coefficient $=1,821 \in(1.5 ; 2.5)$, so no first-order correlation occurs.

(iii) Testing F has Sig coefficient. $=0.000<0.05$, so the model fits a dataset and can be used.

(iv) The standard deviation is 0.973 close to 1 , so the residual distribution approximates the standard or in other words assumes the normal distribution of the residual is not violated.

Table 6

Multiple linear regression model for unused customer group

\begin{tabular}{|c|c|c|c|c|c|c|c|}
\hline & \multirow{2}{*}{ Model } & \multicolumn{2}{|c|}{ Unstandardized Coefficients } & \multirow{2}{*}{$\mathbf{t}$} & \multirow{2}{*}{ Sig. } & \multirow{2}{*}{$\begin{array}{c}\text { Collinearity Statistics } \\
\text { Tolerance }\end{array}$} & \multirow{2}{*}{$\begin{array}{c}\text { Collinearity Statistics } \\
\text { VIF }\end{array}$} \\
\hline & & B & Std. Error & & & & \\
\hline \multirow{6}{*}{1} & (Constant) & -0.739 & 0.421 & -1.753 & 0.083 & & \\
\hline & PE & 0.214 & 0.078 & 2.766 & 0.007 & 0.938 & 1.066 \\
\hline & $\mathrm{EE}$ & 0.358 & 0.085 & 4.242 & 0.000 & 0.783 & 1.278 \\
\hline & SI & 0.195 & 0.073 & 2.655 & 0.009 & 0.96 & 1.042 \\
\hline & SP & 0.257 & 0.066 & 3.874 & 0.000 & 0.724 & 1.38 \\
\hline & RS & 0.326 & 0.079 & 4.13 & 0.000 & 0.74 & 1.352 \\
\hline
\end{tabular}

Regression formula:

$\mathrm{IU}=\mathbf{- 0 . 7 3 9}+\mathbf{0 . 2 1 4} \times \mathrm{PE}+\mathbf{0 . 3 5 8} \times \mathrm{EE}+\mathbf{0 . 1 9 5} \times \mathrm{SI}+\mathbf{0 . 2 5 7} \times \mathrm{SP}+\mathbf{0 . 3 2 6} \times \mathrm{RS}$

From the table we see, the Sig. coefficients of the regression test $t$ regression coefficient of the independent variables are $<0.05$, so these independent variables are meant to explain the dependent variable, none of the variables are excluded from the model. The VIF of the independent variables is $<2$ so no multicollinearity occurs. Regression coefficients are higher than 0.00. Therefore, all the independent variables included in the regression analysis are acting in the same direction as the dependent variables.

\section{For customers who have / are using the service}

(i) Adjusted R2 value is 0.612 , showing that the independent variable put in the regression process affects $61.2 \%$ of the change of the dependent variable, the rest is due to non-model variables and random errors.

(ii) Durbin-Watson coefficient $=1.734 \in(1.5 ; 2.5)$, so no first-order correlation occurs.

(iii) Testing F has Sig coefficient. $=0.000<0.05$, so the model fits a dataset and can be used. 
(iv) The standard deviation is 0.980 close to 1 , so the residual distribution approximates the standard or in other words assumes the normal distribution of the residual is not violated.

Table 7

Multiples linear regression model for groups of customers already in use

\begin{tabular}{|c|c|c|c|c|c|c|c|}
\hline & \multirow{2}{*}{ Model } & \multicolumn{2}{|c|}{ Unstandardized Coefficients } & \multirow{2}{*}{$\mathbf{t}$} & \multirow{2}{*}{ Sig. } & \multirow{2}{*}{$\begin{array}{c}\text { Collinearity Statistics } \\
\text { Tolerance }\end{array}$} & \multirow{2}{*}{$\begin{array}{c}\text { Collinearity Statistics } \\
\text { VIF }\end{array}$} \\
\hline & & B & Std. Error & & & & \\
\hline \multirow{6}{*}{2} & (Constant) & -0.682 & 0.353 & -1.932 & 0.056 & & \\
\hline & PE & 0.176 & 0.069 & 2.549 & 0.012 & 0.91 & 1.099 \\
\hline & $\mathrm{EE}$ & 0.298 & 0.065 & 4.578 & 0.000 & 0.793 & 1.261 \\
\hline & SI & 0.174 & 0.062 & 2.794 & 0.006 & 0.856 & 1.168 \\
\hline & SP & 0.304 & 0.063 & 4.801 & 0.000 & 0.721 & 1.386 \\
\hline & RS & 0.286 & 0.072 & 3.956 & 0.000 & 0.659 & 1.518 \\
\hline
\end{tabular}

Regression formula:

$R U=-0.682+0.176 \times P E+0.298 \times E E+0.174 \times S I+0.304 \times S P+0.286 \times R S$

From the table we see, the Sig coefficient of the regression test $t$ regression coefficient of the independent variables are $<0.05$, so these independent variables are meant to explain the dependent variable, none of the variables are excluded from the model. The VIF of the independent variables is $<2$ so no multicollinearity occurs. Regression coefficients are higher than 0 . Therefore, all the independent variables included in the regression analysis are acting in the same direction as the dependent variables.

\subsection{Discussion}

Based on the results above, we synthesize the test findings which is presented in Table 8 .

Table 8

Hypothesis test results

\begin{tabular}{|c|c|c|c|c|c|c|}
\hline $\mathbf{H}$ & Hypothesis description & $\begin{array}{l}\text { Custom } \\
\text { group }\end{array}$ & $\begin{array}{l}\text { Influence } \\
\text { coefficient }\end{array}$ & Sig. coefficient & $\begin{array}{c}\text { Test } \\
\text { results }\end{array}$ & $\begin{array}{l}\text { Impact } \\
\text { order }\end{array}$ \\
\hline \multirow{2}{*}{ H1 } & \multirow{2}{*}{$\begin{array}{l}\text { Performance expectation has a positive impact on customer de- } \\
\text { cisions in using mobile payment. }\end{array}$} & Not using & 0.214 & 0.007 & \multirow{2}{*}{ Accept } & 4 \\
\hline & & Using & 0.176 & 0.012 & & 4 \\
\hline \multirow{2}{*}{$\mathrm{H} 2$} & \multirow{2}{*}{$\begin{array}{l}\text { Effort expectation have a positive impact on customers' deci- } \\
\text { sions to use mobile payment services. }\end{array}$} & Not using & 0.358 & 0.000 & \multirow{2}{*}{ Accept } & 1 \\
\hline & & Using & 0.298 & 0.000 & & 2 \\
\hline \multirow{2}{*}{$\mathrm{H} 3$} & \multirow{2}{*}{$\begin{array}{l}\text { The social impact has a positive impact on customers' decisions } \\
\text { to use mobile payment services. }\end{array}$} & Not using & 0.195 & 0.009 & \multirow{2}{*}{ Accept } & 5 \\
\hline & & Using & 0.174 & 0.006 & & 5 \\
\hline \multirow{2}{*}{$\mathrm{H} 4$} & \multirow{2}{*}{$\begin{array}{l}\text { Security and privacy have a positive impact on customers' deci- } \\
\text { sion to use payment services via mobile devices. }\end{array}$} & Not using & 0.257 & 0.000 & \multirow{2}{*}{ Accept } & 3 \\
\hline & & Using & 0.304 & 0.000 & & 1 \\
\hline \multirow{2}{*}{ H6 } & \multirow{2}{*}{$\begin{array}{l}\text { Reputation of suppliers has a positive impact on customers' de- } \\
\text { cisions to use payment services via mobile devices. }\end{array}$} & Not using & 0.326 & 0.000 & \multirow{2}{*}{ Accept } & 2 \\
\hline & & Using & 0.286 & 0.000 & & 3 \\
\hline
\end{tabular}

Specifically, for both groups of customers who have not used and / have been using mobile payment services, among the above 6 hypotheses, there are 05 accepted hypotheses: H1, H2, H3, H4, H6, correspond to determinants of expected effectiveness, expected effort, social impact, safety and security and supplier reputation. The factor of influence of these determinants is $>0$, so all determinants positively influence decisions of unused customers as well as customers who have been / are using mobile payment services. . However, the level of influence varies, for customers who have not used factor services, the expected impact level has the highest impact level of 0.358 , while for customers who have been using nuclear service safety and security determinants have the highest impact level of 0.304 . Social influence determinants have the smallest impact level according to regression results. Particularly, the hypothesis H5 is rejected (from Pearson correlation analysis), the cost sensing factor does not affect the decision of customers not using mobile payment services.

The impact of expected effects is consistent with the research results of Wang \& Yi (2012); Slade et al. (2015a,b); Abrahão et al. (2016). This is consistent with the reality, customers are willing to use any product or service when they feel the effectiveness of that product or service.

The impact of the expected effort is consistent with the findings of Wang \& Yi (2012), Oye et al. (2014). This shows that one of the top concerns of potential customers or current customers for a product or service is whether it is easy to use or not.

The impact of social influence is consistent with the research results of Abrahão et al. (2016); Mun et al. (2017); Tossy (2014). This is consistent with consumer behavior, social determinants (family, reference group, role and social status) that influence consumer purchasing behavior. 
The impact of safety and security is consistent with the findings of Luna et al. (2017), Hahn \& Kodó (2017). Consumers care about the safety and security of the service because they tend to fear personal information, account information being exposed or stolen during using the service.

The impact of supplier reputation is consistent with the findings of), Liu et al. (2009), Chandra et al. (2010). Reputation of suppliers will bring more confidence to customers about products and services, which will make it easier for customers to accept and use those products and services.

\section{Conclusion}

Based on the theory of UTAUT by Venkatesh et al. (2003) combined with reference to previous studies related to topics from many different countries in the world, the author has built a personal model Determinants influencing customers' decision to use payment services via mobile devices in Hanoi city. Determinants such as expected performance, expected effort, social impact, safety and security, supplier reputation have a positive influence on the current and customer service decisions in Hanoi city. Research results show that one of the top concerns of potential customers or current customers for a product or service is whether or not it's easy to use. Consumers, if instructed, experienced the service, the product will feel easy to use and may use or use it more often.

In addition to being concerned about the ease of use, potential consumers and existing consumers also focus on the safety and security of the service. Because they tend to fear personal data, accounts being exposed or stolen during the use of payment services via mobile devices. This partly reflects the habits of Vietnamese consumers when choosing to use cash payment because they feel that using cash will be safer and more reliable than non-cash payment. In addition, the reputation of a provider will bring more confidence of users about products and services, which will make them easier to accept and use that supplier's products and services; customers are willing to use any product or service when they feel the effectiveness of such product or service; social determinants serve as good reference for customers' decision to use the service. This empirical result is of reference value for managers and suppliers in the operation and development of payment services via mobile devices through the integration of more utilities and enhanced user experience, enhance security and privacy, preserve and promote reputation and take advantage of social determinants.

\section{References}

Abrahão, R.D., Moriguchi, S.N., \& Andrade, D.F. (2016). Intention of adoption of mobile payment: An analysis in the light of the Unified Theory of Acceptance and Use of Technology (UTAUT). RAI Revista de Administração e Inovação, 13(3), 221-230.

Al-Qeisi, K. I. (2009). Analyzing the Use of UTAUT Model in Explaining an Online Behaviour: Internet Banking Adoption. Brunel University.

Al-Qeisi, K., \& Al-Abdallah, G. (2013). Internet Banking Adoption in Jordan: A Behavioral Approach. International Journal of Marketing Studies, 5(6), 84-108.

Baptista, G.D. (2016). Mobile banking and mobile payment acceptance. NOVA Information Management School.

Chandra, S., Srivastava, S.C., \& Theng, Y.L. (2010). Evaluating the Role of Trust in Consumer Adoption of Mobile Payment Systems: An Empirical Analysis. Communications of the Association for Information Systems, 27, 561-588.

Chellappa, R.K., \& Pavlou, P.A. (2002). Perceived information security, financial liability and consumer trust in electronic commerce transactions. Logistics Information Management, 15(5/6), 358-368.

Chong, A.Y.L. (2013). Understanding mobile commerce continuance intentions: An empirical analysis of Chinese consumers. Journal of ComputerInformation Systems, 53(4), 22-30.

Cronbach, L. J. (1951). Coefficient alpha and the internal structure of tests . Psychometrika, 16(3), $297-334$.

Dahlberg, T., Mallat, N., Ondrus, J., \& Zmijewska, A. (2008). Past, present and future of mobile payments research: a literature review. Electronic Commerce Research and Applications, 7(2), 165-181 .

Davis, F. D., Bagozzi, R., \& Warshaw, P. R. (1989). User Acceptance of Computer Technology: A Comparison of Two Theoretical Models. Management Science, 35(8), 982-1002.

Do, T.N. (2016). Factors Influencing the Usage of Internet Banking of Customers in Vietnam Commercial Banks. Master Thesis, National Economic University.

Doney, P.M., \& Cannon, J.P. (1997). An Examination of the Nature of Trust in Buyer-Seller Relationships. Journal of Marketing Research, 61, 35-51.

EPC. (2017). EPC492-09 White paper mobile payments. Version 5.0 edition 2017.

Fan, Y., Saliba, A., Kendall, E.A., \& Newmarch, J. (2005). Speech interface: an enhancer to the acceptance of m-commerce application. Proceedings of The International Conference on Mobile Business (ICMB'05). Sydney.

Fernandes, C., \& Awamleh, R. (2006). Diffusion of internet banking amongst educated consumers in a high income nonOECD country. Journal of Internet Banking and Commerce, 11(3), 1-17.

Ghezzi, A., Renga, F., Balocco, R., \& Pescetto, P. (2010). Mobile payment applications: Offer state of the art in the Italian market. Info, 12(5), 3-22.

Hahn, I.C., \& Kodó, K. (2017). Acceptance of Online and Mobile Payment. Halmstad Univerity.

Hair Jr, J.F., Black, W.C., Babin, B.J., \& Anderson, R.E. (2009). Multivariate Data Analysis, Seventh Edition. London: Pearson. 
Hosein, N.Z. (2009). Internet Banking: An Empirical Study of Adoption Rates among Midwest Community Banks. Journal of Business \& Economics Research, 7(11), 51-72.

Imran, M., Hamid, S., Aziz, A \& Hameed, W. (2019). The contributing factors towards e-logistic customer satisfaction: a mediating role of information technology. Uncertain Supply Chain Management, 7(1), 63-72.

Kartalia, J. (2000). Reputation at Risk? Risk Management, 4(7), 51-58.

Kim, D. J., Ferrin, D. ., \& Rao, H. . (2008). A trust-based consumer decision-making model in electronic commerce: The role of trust, perceived risk, and their antecedents. Decision support systems, 44(2), 544-564.

Koenig-Lewis, N., Marquet, M., Palmer, A. ., \& Zhao, A. (2015). Enjoyment and social influence: predicting mobile payment adoption. The Service Industries Journal, 35(10), 537-554.

Lau, G., \& Lee, S. (1999). Consumers' Trust in a Brand and the Link to Brand Loyalty. Journal of Market-Focused Management, 4(4), 341-370.

Lesa, E. (2016). Study on influential factors of mobile payment systems diffusion in Zambia: a NFC-micro SD perspective. The university of Zambia.

Liu, Z., Min, Q., \& Ji, S. (2009). An empirical study on mobile banking adoption: The role of trust. Second International Symposium on Electronic Commerce and Security, 2, 7-13.

Luarn, P., \& Lin, H.-. (2005). Toward an understanding of the behavioral intention to use mobile banking. Computers in Human Behavior, 21(6), 873-891.

Luna, I. ., Montoro-Ríos, F., Liébana-Cabanillas, F., \& Luna, J. . (2017). NFC technology acceptance for mobile payments: A Brazilian Perspective. Review of Business Management, 19(63), 82-103.

Mallat, N. (2007). Exploring consumer adoption of mobile payments-A qualitative study. The Journal of Strategic Information Systems, 16(4), 413-432.

McKnight, D., Cummings, L. ., \& Chervany, N. (1998). Initial trust formation in new organizational relationships. Academy of Management Review, 23(3), 473-490.

Moore, G. ., \& Benbasat, I. (1991). Development of an instrument to measure the perceptions of adopting an information technology innovation. Information Systems Research, 2(3), 173-191.

Mun, Y.P., Khalid, H., \& Nadarajah, D. (2017). Millennials’ Perception on Mobile Payment Services in Malaysia. Procedia Computer Science, 124, 397-404.

Nguyen, P., Lee, S. , \& Kang, W. (2015). An Empirical Study on Factors Affecting Customer Intention to Use Mobile Payment System in Vietnam. Journal of Information Technology Services, 14(4), 171-184.

Nguyen, T.N., Cao, T.K., Dang, P.L., \& Nguyen, H A. (2016). Predicting Consumer Intention to Use Mobile Payment Services: Empirical Evidence from Vietnam. International Journal of Marketing Studies, 8(1), 117-124.

Nguyen, D.T. (2013). Methods of scientific research in business. Finance Publishing House, $2^{\text {nd }}$ Edition.

OECD. (2012). Report on Consumer Protection in Online and Mobile Payments.

Oye, N.D., Lahad, N., \& Rahim, N.Z. (2014). The history of UTAUT modeland its impact on ICT acceptance and usage by academicians. Educationand Information Technologies, 19, 251-270.

Pham, T.T., \& Liu, G.S. (2016). An Analysis of Factors Affecting the Intention to Use Mobile Payment Services in Vietnam. Economics World, 4(6), 249-273.

Shafinah, K., Sahari, N., Sulaiman, R., Yusoff, M.S., \& Ikram, M.M. (2013). Determinants of user behavior intention (BI) on mobile services: A preliminary view. The 4th International Conference on Electrical Engineering andInformatics (ICEEI) (pp. 127-133). Procedia Technology.

Slade, E.L., Williams, M.D., Dwivedi, Y.K., \& Piercy, N. (2015a). Exploring consumer adoption of proximity mobile payments. Journal of Strategic Marketing, 23(3), 209-223.

Slade, E.L., Dwivedi, Y.K., Piercy, N., \& Williams, M.D. (2015b). Modeling consumers' adoption intentions of remote mobile payments in the UK: Extending UTAUT with innovativeness, risk and trust. Psychology \& Marketing, 32(8), 860873.

Tossy, T. (2014). Modelling the Adoption of Mobile Payment System for Paying Examination Fees in Tanzanian Major Cities. International Journal of Computing and ICT Research, 8(2), 83-98.

Truong, T., Phan, H \& Tran, M. (2020). A study on customer satisfaction on debit cards: The case of Vietnam. Uncertain Supply Chain Management, 8(2), 241-251.

Venkatesh, V., Morris, M.G., Davis, G.B., \& Davis, F.D. (2003). User acceptance of information technology: Toward a unified view. MIS Quartely, 27(3), 425-478.

Venkatesh, V., Thong, J.Y., \& Xu, X. (2012). Consumer acceptance and use of information technology: extending the unified theory of acceptance and use of technology. MIS Quarterly, 36(1), 157-178.

Wang, L., \& Yi, Y. (2012). The impact of use context on mobile payment acceptance: An empirical study in China. In A. Xie, \& X. Huang, Advances in computer science and education (pp. 293-300). Berlin: Springer.

Xin, H., Techatassanasoontorn, A.A., \& Tan, F.B. (2015). Antecedents of Consumer Trust in Mobile Payment Adoption. Journal of Computer Information Systems, 55(4), 1-10.

Yang, S., Lu, Y., Gupta, S., Cao, Y., \& Zhang, R. (2012). Mobile payment services adoption across time: An empirical study of the effects of behavioral beliefs, social influences, and personal traits. Computers in Human Behavior, 28(1), $129-142$.

Yeh, M.L., \& Tseng, Y.L. (2017). The college students' behavior intention of using mobile payments in taiwan: an exploratory research. Proceedings of IASTEM International Conference. Singapore.

Yousafzai, S., Pallister, J., \& Foxall, G. (2003). A proposed model of e-trust for electronic banking. Technovation, 23(11), 
847-860.

Zhang, Y., Sun, J., Yang, Z., \& Wang, Y. (2018). What Makes People Actually Embrace or Shun Mobile Payment: A CrossCulture Study. Mobile Information Systems, 2018, 1-13.

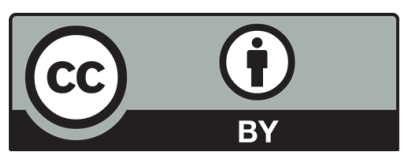

(C) 2020 by the authors; licensee Growing Science, Canada. This is an open access article distributed under the terms and conditions of the Creative Commons Attribution (CC-BY) license (http://creativecommons.org/licenses/by/4.0/). 